\title{
Türkiye' de İşsizlik Histerisi Hipotezinin Geçerliliği: Çok Boyutlu ve Asimetrik Yaklaşım
}

\author{
DOI: $10.26466 /$ opus.725553
}

*

\section{Musa Öztürk *}

* Dr. Öğr. Üyesi, Isparta Uygulamalı Bilimler Üniversitesi, Bankacılık ve Sigortacılık Bölümü E-Posta: musaozturk@isparta.edu.tr

ORCID: 0000-0002-0902-5787

\section{Öz}

İssizlik; sosyoekonomik ve politik analizlerin kesişsim kümesindedir ve bunlar arasındaki işleyişin varlığı, yönü ve ivmesi hakkındaki tartısmalarm hem neden ve hem de sonuç kısımlarında yer almaktadır. Bu nedenle; insanların, toplumlarm ve devletlerin bugünkü durumlarmın anlaşılması ve gelecek beklentilerinin oluşmasında kritik öneme sahip olan işsizlik verisinin incelenmesi, serilerdeki değişimlerin analiz edilmesi ve modellenmesi oldukça önemlidir. Çalışma kapsamında işsizlik oranlarında yaşanan şokların kalıcllğ̆ı, histeri analizi kapsaminda simetrik ve asimetrik olarak sorgulanmaktadır. Bu doğrultuda 2005 Ocak ile 2019 Ağustos arası dönemi kapsayan aylık veriler, Augmented Dickey-Fuller, Phillips-Perron ve yapısal kırılmalı birim kök testi olan Lee-Strazicich testleriyle iki aşamah olarak incelenmektedir. Birinci aşamada, bardă̆gn dolu tarafin göstermek üzere, işgücüne katılım ve istihdam oranlarn ile bu serilerdeki pozitif ve negatif şoklardaki değiş̧meler ele alınmaktadır. Bardağın boş olduğu tarafa odaklanan ikinci aşamada da genel, genç ve tarım dışı işsizlik oranları ile bu serilerdeki pozitifve negatif şoklardaki değ ̧̧şimleri ifade eden seriler incelenmektedir. Elde edilen analiz bulgularnna göre işsizlik histerisi hipotezi, işgücüne katıllm, istihdam ve genç işsizlik serileri için geçerlidir ve bu seriler şoklar sonrasında kendiliğinde dengeye gelememektedirler. Genel ve tarım dışı işsizlik verileri için yapısalcı yaklaşım geçerlidir ve bu seriler yapısal kurılmalara uğramakla birlikte makroekonomik bir müdahaleye gerek olmaksızın kendiliğinden dengeye gelebilmektedir. Bu sonuçlara ilave olarak çalışmada seriler asimetrik şoklarma ayrıştırllarak değerlendirilmiştir. Buna göre istihdam oranmın pozitif şoklarmdan oluşan seri ile genel, genç ve tarım dışı istihdam serilerine ait pozitif ve negatif şoklar gösteren seriler için histeri etkisinin geçerli olduğu, şoklarn kalıc etkilerde bulunduğu tespit edilmiştir. Elde edilen sonuçlar histeri etkisinin nedenleri kapsamında ilgili literatüre göre tartışlmış ve teknolojik dönüşüm modeli ile yeni sayfa yaklaşımı olarak iki farklı önermede bulunulmuştur. Sonuç olarak başta genç işsizlik oranlar olmak üzere histeri hipotezinin geçerli olduğu durumlarda sosyoekonomik ve politik anlamda istikrarın sağlanması için otoritelerin makroekonomik müdahalelerde bulunmaları gerektiğ i tespit edilmiştir.

Anahtar Kelimeler: Gizli Histeri, Asimetrik İşizlik Histerisi, Teknolojik Dönüşüm Modeli, Yeni Sayfa Yaklaşımı 


\title{
Validity Of The Unemployment Hysteresis Hypothesis In Turkey: Multidimensional And Asymmetrical Approach
}

\begin{abstract}
Unemployment is at the intersection of socioeconomic and political analyses; it is included in both cause, and effect sections of the discussions about the existence, direction, and acceleration of these analyses. Therefore, it is very important to examine the unemployment data, analyze and model the changes in the series, to understand the current situation of people, societies, and states and to form the expectations for the future. In the study, the permanence of the shocks experienced in unemployment rates is questioned symmetrically and asymmetrically within the scope of the hysteresis hypothesis. Accordingly, monthly data covering the period between January 2005 and August 2019 are analyzed in two stages by Augmented Dickey-Fuller, Phillips-Perron, and Lee-Strazicich structural break unit root test. In the first stage, labor force participation and employment rates and changes in positive and negative shocks in these series are discussed to show the full side of the glass. In the second phase, which focuses on the empty side of the glass, the series expressing general, young, and non-agricultural unemployment rates and the changes in positive and negative shocks in these series are examined. According to the analysis findings obtained, the unemployment hysteresis hypothesis is valid for labor force participation, employment, and youth unemployment series and these series cannot automatically balance aftershocks. The structuralist approach is valid for general and non-agricultural unemployment data, and these series may suffer from structural breaks, but can automatically stabilize without the need for a macroeconomic intervention. In addition to these results, the series was evaluated by decomposing into asymmetric shocks. Accordingly, the hysteresis effect is valid for the series consisting of positive shocks of the employment rate. Also, it is determined that the hysteresis effect is valid and the shocks have permanent effects for the series showing the positive and negative shocks of the general, young and non-agricultural unemployment series. As a result, it was determined that the authorities should make macroeconomic interventions to ensure socioeconomic and political stability when the hysteresis hypothesis, especially for the youth unemployment rates, is valid.
\end{abstract}

Keywords: Hidden Hysteresis, Asymmetric Unemployment Hysteresis, Technological Transformation Model, New Page Approach 


\section{Giriş}

Küreselleşme sürecinde yaşanan dönüşümler dünya genelinde sosyoekonomik ve politik şokların ortaya çımasına neden olmaktadır. Bu şokların hem nedeni ve hem de sonucu olabilen değişkenlerden biri işsizliktir. İşsizlik emek faktörünün tam ve/veya etkin kullanılmamasın ifade etmektedir ve emek, üretim ve tüketim ilişkilerinin bir arada alındığı yegâne üretim faktörü olarak diğerlerinden ayrılmakta, şokları taşıyıı ve tetikleyici özellikler gösterebilmektedir. Tokatlığlu vd. (2014, s.299)'nin ifadesiyle günümüzde ülkeler ve dünya ölçeğinde en çok tartışlan makroekonomik olgulardan biri haline gelen işsizlik, az gelişmiş ve gelişmekte olan ülkeler başta olmak üzere bütün ekonomiler için öncelikli konulardan biridir.

Türkiye için de ayn durum geçerlidir ve işsizlik en önemli makroekonomik sorun olarak ülke gündeminin değişmezleri arasındadır. Bu nedene ilgililer tarafından hassasiyetle takip edilmektedir (Çelik ve Küçükkale, 2018, s.22). Özellikle de genç nüfusun yoğun olması konunun önemini arttırmaktadır (Bozkurt ve Altıner, 2018, s.168). Yapılan saha araştırmaları da Türkiye'de halkın en büyük sorun olarak ifade ettiği konulardan birinin işsizlik olduğunu işaret etmektedir (CTRS). İşsizlik oranlarının; 1980'de \%7,2, 1990 'da \%8, 2000'de \%6 ve 2000 sonrasında ortalama \%10,1 dolaylarında seyretmesi ve 1980 'den itibaren eğimin artan şekilde olması sorunun giderek büyümekte olduğunu göstermektedir. 1980'den bugüne geçen süre zarfinda ortalama yıllık \%4,5 dolaylarında ekonomik büyüme kaydedilmesine rağmen işsizlik sorununun giderilemeyişi, ekonomik büyümenin yeteri kadar istihdam üretemiyor olmasını işaret eden 'işsiz büyüme (jobless growth)' kavramı merkezindeki (Tunalı, 2010, s.21) tartısmaları körüklemektedir. Bu süreçte yaşanan kentleşme, teknolojik gelişmeler ve kadın istihdamındaki artış gibi nedenler işsizlik yapılarında birtakım değişmelere neden olsa da bunlar Türkiye'nin OECD ülkeleri içinde -büyük çaplı ekonomik krizler yaşamış olanYunanistan ve İspanya'dan sonra en yüksek işsizlik oranına sahip ülke olduğu gerçeğini değiştirmemektedir.

Genel olarak ekonomik çerçevede ve özellikle de üretim kapasitesindeki rolüyle ele alınan işsizlik aslında sosyolojik ve politik boyutları da içeren çok boyutlu bir kavramdır. İntihar, boşanma, suç eğilimi, göç ve benzeri sosyal boyutları olan bir konu olmasının yanı sıra demokratik ülkelerde seçimlerin kaderini belirleme kabiliyetine sahiptir. Bu nedenle birçok kesim tarafından 
işsizlik oranlarındaki değişimler özenle takip edilmektedir. Çalışmanın konusu istihdam ve işsizlik dinamiklerini çok boyutlu olarak incelemektir. Bu amaç doğrultusunda işgücüne katılım, istihdam oranları, genel işsizlik oranı, genç işsizlik oranı ve tarım dışı işsizlik oranı ve bunlardaki pozitif ve negatif şokları ifade eden seriler ayrı ayrı ele alınarak, şokların kalıcılığı araştırılmaktadır. Çalışmanın özgünlüğü, bir taraftan işgücüne katılım ve istihdam oranların ele alıyor olması, diğer taraftan da analize dahil edilen seriler ait pozitif ve negatif şoklardaki kalıcılığının ayrı ayrı sınanmasıdır. Bu doğrultuda takip eden bölümde ilgili literatür özetine ardından da metodoloji, ampirik bulgular ve değerlendirme-sonuç bölümlerine geçilmektedir.

\section{Literatür Özeti}

İşsizlik oranlarının seyri ve şoklar karşısında sergilediği karakteristiği toplum ve politika uygulayıcılar başta olmak üzere birçok kesim için önemlidir. Çok boyutlu ve karmaşık bir olgu olan işsizlik dinamiklerine dair incelemeler, özellikle 1970'lerdeki şoklarının etkisiyle oluşan arz-talep dengesizliğinden kaynaklı olarak artan işsizlik oranlarının beklentilerden farklı özellik göstermesi nedeniyle araştırmalara konu olmaya başlamıştır (O'Shaughnessy, 2011, s.312; Doğru, 2014, s.78; Karagöz ve Saraç, 2016, s.61; Bozkurt ve Altıner, 2018, s.168). Özellikle, 1973-74 ve 1979-80 yıllarında yaşanan gelişmeler ve petrol krizleri neticesinde oluşan şoklar neticesinde Avrupa' da işsizlik oranlarının yaklaşık \%10 yükselmesi ve kriz sonrasında eski düzeyine dönememesi (Çınar vd., 2014, s.30) ve benzer durumun 2008-2009 yıllarında yaşanan Küresel Finans Krizi'nden sonra da gerçekleşmesi konunun yeniden ele alınmasını ve tartışmaların bu alana yoğunlaşmasını sağlamıştır (Kahyaoğlu vd., 2016: 105; Baysal Kar, 2019, s.279).

Tartışmaların odak noktasında işsizlik verisi başta olmak üzere makroekonomik verilerin kendiliğinden dengeye gelip-gelemeyeceği veya diğer ifadeyle şokların kalıcı etkilerinin bulunduğunu ifade eden histeri etkisinin olup olmadığı yer almaktadır. İktisadi doktrinler merkezinde bu konu ele alınd1ğında piyasa mekanizması ve görünmez elin koordinasyonuna vurgu yapan klasik ekolün değişkenlerin dengeye yakınsayacağını vurguladığı görülmektedir. Değişkenlerin şoklar sonrasında dengeye yönelmesi konusunda bir fikir birliği olmasına karşın pratikte farklı sonuçların ortaya çıkıyor olması çeşitli hipotezlerin ortaya atılmasını sağlamaktadır. 
İşsizlik verisinin şoklar karşısında sergilediği karakteristiği üzerine yapılan tartışmalarda, doğal oran hipotezi, işsizlik histeri hipotezi ve yapısalcı yaklaşım olarak üç temel yaklaşım öne çıkmaktadır (Özcan, 2012, s.96). İşsizlik oranlarının uzun dönemde enflasyonu hızlandırmayacak bir denge düzeyine yakınsayacağını ifade eden Phelps (1967) ve Friedman (1968) doğal işsizlik oranı yer almaktadır. Buna göre, genel olarak, çalışmaya elverişli olup ve çalışmak isteyip de iş bulamayanların toplam işgücüne oranı olarak ele alınan işsizlik oranlarındaki şoklar kalıcı değildir ve uzun dönemde ekonomi enflasyonu hızlandırmayan işsizlik oranına (non-accelerating infltion rate of unemployment-NAIRU) doğru yakınsayacak, her ekonomi uzun dönemde kendi dinamiklerine özgü doğal işsizlik oranında dengeye gelecektir (Güriş vd., 2015, s.2). Blanchard ve Summers (1986) ise ilk kez Ewing (1881)'in ürettiği, Samuelson'un (1965) ekonomi literatürüne, Phelps'in de (1972) işsizlik analizinde kullandığı işsizlik histerisi yaklaşımını (Roed, 1996: 590) pekiştirerek işsizlik oranları üzerindeki şokların kalıcı etkilerinin bulunduğunu ifade eden histeri hipotezini ortaya atmışlardır. Buna göre seride yaşanan şoklar sonrasında yeni normal oluşmakta ve yeni genel denge bu oran etrafında şekillenmektedir (Doğru, 2014, s.77-78). Phelps (1994) yılındaki çalışmasında ise doğal işsizlik oranının makroekonomik değişkenlerden, kurumsal işleyişten ve benzeri endojen dinamiklerken etkilenebildiğini ifade etmekte ve yapısal kırılmaların dikkate alınması gerektiğini belirtmektedir. Hangi hipotez ve yaklaşımın geçerli olduğu ekonometrik açıdan birim kök testleriyle incelenmektedir. Eğer seri durağan yani I(0) ise yaşanan şoklar kalıcı etkide bulunmuyor demektir ve bu doğal oran hipotezinin geçerli olduğunu işaret eder. Seri birim kök içeriyorsa, I(1) ise histeri etkisi geçerlidir. Yapısalcı yaklaşım ise işsizlik düzeyinin genellikle yapısal kırılmalardan etkilendiği noktasından hareketle işsizlik oranlarının yapısal kırılmalara izin verildiğinde durağan hale geldiğini işaret etmektedir (Romero-Avila ve Usabiaga, 2007: 698-699, Özcan, 2012, s.97-98; Bozkurt ve Altıner, 2018, s.168).

İşsizlik oranlarındaki histeri etkisinin nicel bakımdan değişmesi özellikle enflasyon ile işsizlik arasında değiş tokuşun (trade-off) olduğunu işaret eden Phillips eğrisinde önemlidir (Akkuş ve Topuz, 2019, s.70). Beklentilerle genişletilmiş Phillips eğrisi yaklaşımı en sade haliyle; $p_{t}=p_{t-1}+\beta\left(U_{t}-U_{t}^{*}\right)$ 
şeklinde gösterilebilir. Burada; $p_{t-1}$ beklenen enflasyon oranı, $p_{t}$ cari enflasyon oranı, $U_{t}$ cari işsizlik oranı, $U_{t}^{*}$ doğal işsizlik oranı ve $\beta$ Phillips eğrisinin eğimini göstermektedir. Doğal işsizlik oranı olan $U_{t}^{*}$; geçmiş gözlemlerin bir fonksiyonu $\alpha U_{t-1}$ ve mikro ekonomik belirleyicilerin-dengelerin yansıması $Z_{t}$ değişkenlerinin toplamıdır, $U_{t}^{*}=\alpha U_{t-1}+Z_{t}$. İki denklem bir arada ele alınırsa $p_{t}=p_{t-1}+\beta\left(U_{t}-\alpha U_{t-1}-Z_{t}\right)$ denklemine ulaşılır. Burada eğer $\alpha=1$ ise bu durum seride birim kökün varlığını, tam histeri etkisinin olduğunu, yani doğal işsizlik oranın değiştiğini ve ayrıca enflasyon ile işsizlik arasında değiş-tokuşun olduğunu ifade etmektedir (Çınar et al. 2014: 31-32). $0<\alpha<1$ olması durumunda histeri kavramı yerine dengeye gelmenin uzun dönemde gerçekleşeceğini işaret eden kalıcılık-süreklilik (persistency) kavramı öne çıkmaktadır (Özcan, 2012, s.98; Mitchell ve Joan, 2008, Camarero vd., 2006).

İşsizlik oranlarında histeri etkisinin geçerli olmasının nedenleri üzerine yapılan tartışmalarda Blanchard ve Summers (1986) öne çıkmaktadır. Avrupa ülkelerindeki işsizlik oranlarını inceleyen bu araştırmacılara göre histeri etkisin ortaya çıkması; fiziki sermaye, beşerî sermaye ve içerdekiler-dışardakiler modelleri olarak üç farklı şekilde açıklanabilir. İlk olarak fiziki sermaye modeli; ekonomik daralma süreçlerinde firmaların sermaye stokunda azalmaya gideceğini (negatif arz şoku) ve böylece sonraki dönem için emek talebinde daralmaların olacağını ve böylece şokların uzun dönemli işsizliği tetikleyeceğini ifade etmektedir. Beşerî sermaye modeli; şokların işsiz kalan işgücünün becerilerini ve motivasyonlarını kaybetmelerine neden olacağını, firmaların da uzun dönemli potansiyeli olan gençlere yöneleceğini belirtmektedir. Bu durum bir taraftan erken emeklilik ve yarı çalışma imkânı olan orta yaşlıların piyasadan çekilmelerine neden olurken, diğer taraftan nitelikli emek sahibi olan işgücünün istihdam edilmesini sağlayacaktır. Böylece toplam emek talebi daralacak ve histeri etkisi ortaya çıkacaktır. Üçüncü yöntem ise Linbeck ve Snower (1985) ile Gregory (1985)'ın katkılarıyla şekillendirilen içerdekiler-dışardakiler modelidir. Buna göre ücretler üzerinde pazarlık yapabilme kabiliyetinde olan sadece içerdekilerdir (çalışanlar-müstahdem) ve dışardakilerin (işsizlerin) bu konuda hiçbir rolü yoktur. İçerdekiler dışardakilerin istihdam koşullarını değil kendi işlerini devam ettirmekle ilgilenirler. 
İçerdekiler gerek firma içinde oldukları gerekse de sendika vb. oluşumlarla örgütlü hareket ederek monopol gibi davranabildikleri için firmanın emek talebi hakkında önceden bilgi sahibi olabilirler ve bu durumda kendi faydalarını maksimize edecek adımlar atarak dışardakileri dışarda tutmayı başarurlar. Bu durumda işsizlik oranlarınn histeri özelliği göstermesine neden olur (Blanchard ve Summers, 1986, s.27-29).

Blanchard ve Summers (1986)'a paralel olarak Pissarides (1992) işsizlerin sahip oldukları becerilerini zaman içinde kaybettiklerini ve bu nedenle şok sonrası işsizlik serilerinin başlangıç düzeyine gelmede sorun yaşadığını işaret etmektedir. Sessions (1994) ise Simon (1957) atıfla neoklasik aksiyomlar arasinda yer alan "rasyonel ekonomik insan" kabulünün reddedilmesini vurgulayarak başladığı çalışmasında, Akerlof (1984)'un davranışsal yaklaşımını takip ederek işsizliği psiko-sosyal boyutlarıyla ele almıştır. Genel kabule göre iyi bir işte çalışmanın prestij, kötü bir işte çalışmanın da "damga-leke, stigma" olduğunu belirten Sessions, uzun süren işsizliğin de bir tür damgalanma olduğunu ve damgalanan işgücünün gereken iletişim ve etkileşim kanallarından uzaklaştığını ve bu süreçte verimlilik ücretindeki artışı getirmek suretiyle istihdamdaki azalmayı kalıcı hale getirdiğini ifade etmektedir. Christopoulas ve Leon-Ledesma $(2007$, s.81) ise bunlara ilave olarak işten çıkarma, sermaye kısıtları, koordinasyon eksiklikleri-hatası gibi kurumsal nedenlerin histeri etkisinin ortaya çımasında etkili olabileceğini belirtmektedir.

Bu çalışmada histeri etkisinin ortaya çıkmasına dair yaklaşımlara yeni bir bakış açısı olarak teknolojik dönüşüm modeli (technological transformation model) ve yeni sayfa yaklaşımı (new page approach) önerilmektedir. Teknolojik dönüşüm modeline göre; üretim, yönetim ve tüketim süreçlerinde içselleştirilen teknolojinin oldukça hızlı bir şekilde gelişiyor olması, şokların etkisiyle işsiz kalan kesimin yeni istihdam edilen teknolojilere uyum sağlayamamaları nedeniyle işsizliklerin kalıcı hale gelmektedir. Ilave olarak yeni teknolojilerin, yüksek ücretlerle çalışan kesimlerin faaliyetlerini taklit etmeye yönelmesi sonucunda fazla nitelik aranmayan ara eleman talebi artmaktadır ve bu da eğitimli işsiz sayısında artışa ve bu artışın kalıcı olmasına dolaylı olarak neden olabilmektedir. Yeni sayfa yaklaşımı ise şoklar neticesinde firmaların istihdam ettiği emek miktarını azaltacaklarını ve şok sonrasında yeni bir sayfa açarak firmanın emek talebini azaltacak şekilde daha üst/yeni teknolojiyi içeren yatırımlara yöneleceklerini ifade etmektedir. Teknolojik dönüşüm modeli ve yeni sayfa yaklaşımının işsizlik histerisinin güncel nedenlerinden 
olduğu düşünülmektedir. Blanchard ve Summers'ın (1986) öne sürdüğü beşerî sermaye modelinde uzun süreli işsizliğin beceri ve motivasyon kaybına nedene olmasından kaynaklı olarak histeri etkisinin ortaya çıacağı modellenirken teknolojik dönüşüm modelinde bu dönüşüme ayak uydurulamadığı ve uyum sağlanamadığı için histeri etkisinin ortaya çıkacağı belirtilmektedir. Firma ölçeğinde bakıldığında yeni sayfa yaklaşımının teknolojik dönüşüm modelinin etkisini perçinleyeceği ve bu durumdan özellikle de ileri teknolojiye adapte olamayan gençler ve yaş grubundaki işgücünün çokça etkileneceği görülmektedir.

İşsizlik oranlarının sahip olduğu önem ve sosyoekonomik ve politik etmenlerden doğrudan ve dolaylı olarak etkileniyor olması, histeri hipotezinin sürekli sorgulanmasını sağlamakta ve bu durum ilgili literatürü canlı tutmaktadır. Oldukça geniş bir literatür olması nedeniyle aşağıdaki tabloda sadece Türkiye'yi analiz eden uygulamalı çalışmalara kronolojik olarak yer verilmektedir.

Tablo 1. Türkiye'yi inceleyen uygulamalı çalışmalar

\begin{tabular}{|c|c|c|c|}
\hline Yazar(lar) & Dönem & Yöntem & Sonuç \\
\hline Küçükkale (2001) & 1950-1995 & Kalman filtre tekniği & $\begin{array}{l}\text { Sadece bazı zamanlarda geçerli } \\
\text { (zayıf) işsizlik histerisi }\end{array}$ \\
\hline $\begin{array}{l}\text { Pazarlıŏglu ve } \\
\text { Çevik (2007) }\end{array}$ & 1939-2005 & Ratchet modeli & Histeri hipotezi geçerli \\
\hline $\begin{array}{l}\text { Barışık ve } \\
\text { Çevik (2008) }\end{array}$ & 1923-2006 & $\begin{array}{l}\text { Doğrusal testlerin yanı sıra yarı } \\
\text { parametrik yöntemler ve yapısal } \\
\text { kırılmalı testler }\end{array}$ & Histeri hipotezi geçerli \\
\hline Yilancı (2009) & 1923-2007 & $\begin{array}{l}\text { Perron (1997), Zivot-Andrews (1992, } \\
\text { ZA), Lumsdaine - Papell (1997, LP) ve } \\
\text { Lee-Strazicich (2003-2004, LM) }\end{array}$ & Histeri hipotezi geçerli \\
\hline Yildirım (2011) & $1923-2010$ & $\begin{array}{l}\text { Bai-Perron (1998-2003, BP), Carrion-i- } \\
\text { Silvestre, Kim ve Perron (2009) } \\
\text { yapısal kırılmalı birim kök testleri }\end{array}$ & Histeri hipotezi geçerli \\
\hline $\begin{array}{l}\text { Güloğlu ve } \\
\text { İspir (2011) }\end{array}$ & $1988-2008$ & $\begin{array}{l}\text { Carrion-i Silvestre (2005) } \\
\text { panel birim kök testi }\end{array}$ & $\begin{array}{l}\text { Sektörel işsizlik oranı doğal işsizlik ora- } \\
\text { nın özel bir türü olan kalıcılığı (persis- } \\
\text { tency) işaret etmektedir. }\end{array}$ \\
\hline $\begin{array}{l}\text { Koçyiğit vd. } \\
\text { (2011) }\end{array}$ & $1923-2010$ & ADF (1981), STAR & $\begin{array}{l}\text { Histeri hipotezi (zayıf olmakla } \\
\text { birlikte) geçerlidir. }\end{array}$ \\
\hline Özcan (2012) & - & LM ve Im vd. $(2005,2010)$ & $\begin{array}{l}\text { Çoğu OECD ülkesinde histeri } \\
\text { hipotezi geçerlidir. }\end{array}$ \\
\hline Çınar vd. (2014) & $1988-2008$ & $\begin{array}{l}\text { ADF, Phillips-Perron (1988), } \\
\text { Ng-Perron (1995) }\end{array}$ & Yapısalcı yaklaşım geçerlidir. \\
\hline Saraç (2014) & $\begin{array}{l}\text { 2005:01- } \\
\text { 2013:07 }\end{array}$ & $\begin{array}{l}\text { ADF, PP, KPSS (1992), } \\
\text { Caner ve Hansen (2001) }\end{array}$ & $\begin{array}{l}\text { Yapısal kırılmasız testlere göre histeri, } \\
\text { yapısal kırılmalı ve doğrusal olmayan } \\
\text { testlere göre doğal oran hipotezi geçerli }\end{array}$ \\
\hline
\end{tabular}




\begin{tabular}{|c|c|c|c|}
\hline $\begin{array}{l}\text { Tokatlıoğlu } \\
\text { vd. (2014) }\end{array}$ & 1988-2011 & $\begin{array}{l}\text { Ratchet modeli ve Arellano-Bond (1991) } \\
\text { GMM- Dinamik Panel Veri }\end{array}$ & $\begin{array}{l}\text { Histeri hipotezi (zayıf olmakla birlikte) } \\
\text { geçerli }\end{array}$ \\
\hline Bayrakdar (2015) & 2000-2013 & ADF, PP, KPSS ve LM & Histeri hipotezi geçerli \\
\hline $\begin{array}{l}\text { Karagöz ve } \\
\text { Saraç (2016) }\end{array}$ & $\begin{array}{l}\text { 2005:01- } \\
\text { 2016:03 }\end{array}$ & $\begin{array}{l}\text { Kalman filtresi ve eşik değer } \\
\text { regresyon }\end{array}$ & Histeri hipotezi geçerli \\
\hline $\begin{array}{l}\text { Kahyaoğlu } \\
\text { vd. (2016) }\end{array}$ & $\begin{array}{l}\text { 2001Q1- } \\
\text { 2015Q4 }\end{array}$ & Fourier-ADF ve Fourier IPS & Histeri hipotezi geçerli \\
\hline Ă̆azade (2016) & $\begin{array}{l}\text { 2005:01- } \\
\text { 2015:09 }\end{array}$ & $\begin{array}{l}\text { ADF, Kapetanios vd. (2003), Sollis } \\
\text { (2009), Cuestas ve Ordóñez (2014) }\end{array}$ & $\begin{array}{l}\text { Genel, genç ve tarım dışı işsizlik için his- } \\
\text { teri hipotezi geçerli }\end{array}$ \\
\hline $\begin{array}{l}\text { Topalhan } \\
\text { vd. (2017) }\end{array}$ & $\begin{array}{l}\text { 1988:Q3 } \\
\text { 2015:Q3 }\end{array}$ & $\begin{array}{l}\text { Dickey ve Fuller (1979), Said ve Dickey } \\
\text { (1984) ile Lumsdaine ve } \\
\text { Papell (1997) }\end{array}$ & $\begin{array}{l}\text { Doğal oran hipotezi geçerli, yapısal kırıl- } \\
\text { malar etkili }\end{array}$ \\
\hline $\begin{array}{l}\text { Idikut Özpençe } \\
\text { ve Ergen (2017) }\end{array}$ & $\begin{array}{l}\text { 2005:01- } \\
\text { 2016:11 }\end{array}$ & LM & Histeri hipotezi geçerli \\
\hline $\begin{array}{l}\text { Kutlu ve } \\
\text { Yurttagüler (2017) }\end{array}$ & $\begin{array}{l}\text { 2005:01- } \\
\text { 2016:09 }\end{array}$ & $\begin{array}{l}\text { Uzun Hafıza Modeli, ARFIMA } \\
\text { Modeli, GPH Yöntemi }\end{array}$ & $\begin{array}{l}\text { Uzun dönemde doğal oran hipotezi ge- } \\
\text { çerli }\end{array}$ \\
\hline $\begin{array}{l}\text { Yavuzaslan } \\
\text { vd. (2017) }\end{array}$ & $\begin{array}{l}\text { 2005:01- } \\
\text { 2017:02 }\end{array}$ & ADF, PP, Kapetanios (2005) & Genç işsizlik için histeri hipotezi geçerli \\
\hline $\begin{array}{l}\text { Taş ve Ŭ̆ur } \\
\text { (2017) }\end{array}$ & $1980-2013$ & ADF, PP, LM & Histeri hipotezi geçerli \\
\hline $\begin{array}{l}\text { Çelik ve } \\
\text { Küu̧ükkale (2018) }\end{array}$ & $\begin{array}{l}\text { 1988S2- } \\
2015 S 1\end{array}$ & Ratchet modeli & $\begin{array}{l}\text { Histeri etkisi genel, kadın, erkek, genç ve } \\
\text { tarım dışı işsizlik için geçerli, yetişkin iş- } \\
\text { sizliği için geçerli değil }\end{array}$ \\
\hline $\begin{array}{l}\text { Yildırım ve } \\
\text { İnançlı (2018) }\end{array}$ & $\begin{array}{l}\text { 2005:01- } \\
\text { 2016:07 }\end{array}$ & $\begin{array}{l}\text { ADF, KSS, KPSS, FADF, } \\
\text { FKSS ve FKPSS }\end{array}$ & Histeri hipotezi geçerli değil \\
\hline Akcan (2018) & 2005-2017 & ADF ve PP & $\begin{array}{l}\text { Histeri hipotezi tarım sektörü ve tarım } \\
\text { dışı işsizlik için geçerli }\end{array}$ \\
\hline Şanlı (2018) & 1980-2016 & ADF, PP, CADF ve CIPS & $\begin{array}{l}\text { Doğal oran hipotezi desteklenmemekte } \\
\text { ve zayıf histeri söz konusu }\end{array}$ \\
\hline $\begin{array}{l}\text { Bozkurt ve } \\
\text { Alttner (2018) }\end{array}$ & $1982-2017$ & $\begin{array}{l}\text { ADF, PP, KPSS, ZA, LM, } \\
\text { Kapetanios vd. (2003) }\end{array}$ & $\begin{array}{l}\text { Doğrusal testlere göre doğal oran hipo- } \\
\text { tezi, doğrusal olmayan teste göre de his- } \\
\text { teri hipotezi geçerli }\end{array}$ \\
\hline Tekin (2018) & 2005-2017 & $\begin{array}{l}\text { Becker, Enders \& Lee (2006) } \\
\text { Fourier ve standart ADF }\end{array}$ & Histeri hipotezi geçerli \\
\hline Akcan (2019) & $\begin{array}{l}\text { 2005:01- } \\
\text { 2017:06 }\end{array}$ & ADF ve PP & $\begin{array}{l}\text { Histeri etkisi genç işsizlik oranlarında } \\
\text { genel işsizliğe kıyasla daha çok }\end{array}$ \\
\hline $\begin{array}{l}\text { Akkuş ve } \\
\text { Topuz (2019) }\end{array}$ & 1980-2016 & $\begin{array}{l}\text { ADF, LM, FADF, Fourier LM, } \\
\text { Fourier GLS }\end{array}$ & Histeri hipotezi geçerli \\
\hline $\begin{array}{l}\text { Baysal Kar ( } \\
\text { 2019) }\end{array}$ & 1993-2017 & $\begin{array}{l}\text { ADF, Breusch ve Pagan (1980) } \\
\text { LM test, Bai ve Ng (2010), PANIC, } \\
\text { Hadri ve Kurozumi (2012) }\end{array}$ & $\begin{array}{l}\text { Eşgüdümlü piyasa ekonomileri için his- } \\
\text { teri hipotezi, liberal piyasa ekonomileri } \\
\text { için doğal oran hipotezi geçerli }\end{array}$ \\
\hline
\end{tabular}

İşsizlik oranlarının sahip olduğu kritik önem nedeniyle, histeri hipotezine yönelik çalışmalar hemen her ülke ve bölge için sürekli yapılagelmektedir. $\mathrm{Bu}$ çalışmalarda detaya inilmeksizin genel işsizlik oranlarının ele alınması ve sadece birim kök sınamalarıyla yetiniliyor olması eleştirilere kapı aralamaktadır (Saraç, 2014, s.336). Türkiye'de işsizlik oranlarının doğal oran, histeri ve 
yapısalcı yaklaşım merkezinde tartışıldığı uygulamalı çalışmalar genelleştirilerek incelendiğinde, öncelikle konunun çok farklı tekniklerle araştırıldığ göze çarpmasına rağmen bunlar arasında bulguları sunmanın ötesine geçen -neden ve sonuç ilişkilerini tartışan- çalışmaların oldukça nadir olduğu dikkat çekmektedir. Bu çalışmalarda büyük ölçüde histeri hipotezinin geçerli olduğu sonucuna ulaşılırken, benzer dönemler için bazı çalışmaların farklı sonuçlar yansıtabildiği görülmektedir. Bu durum analizlerin çok boyutlu yapılması gerektiği işaret etmesi bakımından önemlidir.

\section{Yöntem}

Çalışmada; doğal oran hipotezi, histeri hipotezi ve yapısalcı yaklaşımdan hangisinin geçerli olduğunun tespiti için literatürde sıkça kullanılmış olan geleneksel ADF ve PP testi ile yapısal kırılmaları veren LM birim kök testleri yapılmaktadır.

\section{Granger ve Yoon (2002) Serilerin Ayruştırlması ve Asimetrik Analiz}

Granger ve Yoon (2002) yaptıkları bir çalışmada değişkenler arasında eşbütünleşme ilişkisinin olmadığını gördükten sonra serilerin eğer bileşenlerine ayrıştırılırsa bütünde fark edilemeyen örtük-saklı ilişkilerin tespit edilebileceğini ifade etmişlerdir. Serilerin aslında pozitif ve negatif şokların toplamından ibaret olduğunu ifade eden bu yaklaşıma göre hata terimleri $\varepsilon_{1 i}=\varepsilon_{1 i}^{+}+\varepsilon_{1 i}^{-} \quad$ şeklindedir ve değişken $P_{1 t}=P_{1 t-1}+\varepsilon_{1 t}=P_{1,0}+\sum_{i=1}^{t} \varepsilon_{1 i}^{+}+\sum_{i=1}^{t} \varepsilon_{1 i}^{-}$şeklinde pozitif ve negatif şoklarına ayrıştırılabilir. Toplam şoklar da $P_{1 t}^{+}=\sum_{i=1}^{t} \varepsilon_{1 t}^{+} P_{1 t}^{-}=\sum_{i=1}^{t} \varepsilon_{1 t}^{-}$olarak ifade edilebilir (Adigüzel et al., 2016: 245, Hatemi J and Roca, 2014: 8). Bu yöntemle bir seriden pozitif ve negatif şokları gösteren iki yeni seriye ulaşılabilir. Böylece serilerdeki değişimler asimetrik ve daha derinlemesine incelenebilir. 


\section{Lee-Strazicich $(2003,2004)$ İki İçsel Yapısal Kırılmah Birim Kök Testi}

Zivot ve Andrews'in (1992) tek yapısal kırılmayı içsel olarak ele alan ve durağanlık sınamasını yapan testini geliştiren Lee ve Strazicich (2003) serilerde iki yapısal kırılma durumunda durağanlık sınamasına odaklanmışlardır. Lagrange Çarpanının kullanıldığı ve bu nedenle ilgili literatürde yaygın olarak LM (Lagrange Multiplier) testi olarak yer alan testte yapısal kırılmalara sabitte (Model A) ve sabit + trendde (Model C) şeklinde oluşturulan iki model üzerinden ulaşılmaktadır (Temurlenk ve Oltulular, 2007, s.4).

Model A:

$$
\Delta y_{t}=K+\phi y_{t-1}+\beta t+\theta_{1} D U 1_{t}+\theta_{1} D U 2_{t}+\sum_{j=1}^{k} d_{j} \Delta y_{t-j}+\varepsilon_{t}
$$

ModelC:

$$
\begin{aligned}
\Delta y_{t}= & K+\phi y_{t-1}+\beta t+\theta_{1} D U 1_{t}+\theta_{2} D T 1_{t}+\theta_{2} D U 2_{t}+\theta_{2} D T 2_{t}+ \\
& \gamma D T_{t}+\sum_{j=1}^{k} d_{j} \Delta y_{t-j}+\varepsilon_{t}
\end{aligned}
$$

Model A'da serinin ortalamasındaki yapısal kırılma varlığı, Model C'de ise ortalama ve trenddeki yapısal kırılma varlığını incelemektedir dolayısıyla Model C daha üstündür. Modellerde DU1t, DU2t ortalamada değişimleri gösterirken $D T 1_{t}$ ve $D T 2_{t}(T B 2>T B 1+2)$ trenddeki değişimleri gösteren kukla değişkenlerdir. $\Delta$ birinci fark işlemini ifade etmektedir, $\varepsilon_{t}$, varyans terimiyle birlikte beyaz gürültülü (white-noise) hata terimlerini temsil etmektedir; ve $\mathrm{t}=1, \ldots$. T zamanı göstermektedir. $D U_{t}$ ise kukla değişkeni ifade etmektedir ve hipotezler aşağıdaki gibidir (Narayan ve Smyth, 2005, s.11091116):

$$
D U_{t}=\left\{\begin{array}{l}
1 \rightarrow t<T B \\
0 \rightarrow \text { Diğer }
\end{array}\right\} \rightarrow(1) \quad D T_{t}=\left\{\begin{array}{l}
t-T B \rightarrow t>T B \\
0 \rightarrow \text { Diğer }
\end{array}\right\} \rightarrow(2)
$$




\section{Veri, Ampirik Bulgular ve Değerlendirme}

Çalışmada histeri hipotezi iki farklı model üzerinden sorgulanmaktadır. Bunların ilki işgücüne katılım ve istihdam oranların kapsamaktadır. İkinci modelde genel, genç ve tarım dışı işsizlik oranlarını içermektedir. TÜİK'ten elde edilen ve 2005M01-2019M08 dönemlerini kapsayan aylık seriler kullanılmaktadır. İki analizde de ilk olarak seriler sonrasında da serilerin pozitif ve negatif bileşenlerinden oluşan serilerdeki histeri ilişkisi Eviews 9 paket programı ile araştırılmaktadır.

Analizlerde kullanılan değişkenler ve kısaltmaları şöyledir: İKO- işgücüne katılım oranı, İSO- istihdam oranı, İO- işsizlik oranı, GIO- genç işsizlik oranı, TDİO- tarım dışı işsizlik oranı. Değişkenlerdeki pozitif ve negatif şoklar $P$ ve N harfleriyle gösterilmektedir (Örn. Genç işsizlik Oranı serisindeki pozitif şoklar GİP şeklinde gösterilmektedir).

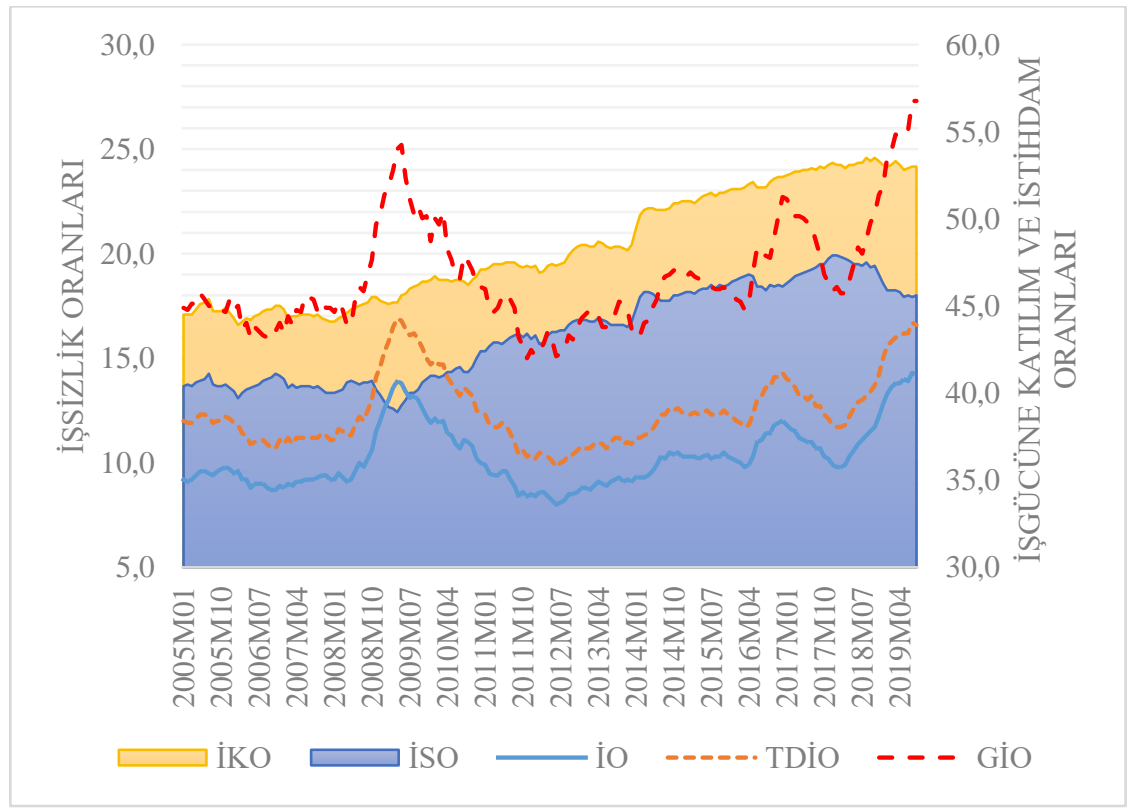

Grafik 1. İşgücüne Katılım, İstihdam, Genel, Genç ve Tarım Dışı İssizizlik Oranlarının Gelişimi (Kaynak: TüIK verilerinden yazar tarafindan hazırlanmıştır.) 
Analizlerdeki serilerin gelişimi incelendiğinde; ilk bakışta 2008 Küresel Finans Krizi'nin ele alınan istihdam türlerinde ciddi bir bozulmaya neden olduğu, aynı şiddette olmasa da buna benzer bir değişmenin 2016 ve 2018 Mart aylarında cereyan ettiği görülmektedir.

Serilere ait tanımlayıcı istatistiki bilgiler aşağıdaki tablo 2' de gösterilmektedir. Toplamda 176 gözlemden oluşan serilerin olasılık değerleri 0,01'den küçüktür. Çarpıklık ve basıklık açısından İKO ve İSO asimetrisi pozitif ve normale göre basıktır. İO, GİO ve TDİO ise asimetrisi pozitif ve normale göre sivridir. Buradan işgücüne katılım ve istihdam oranlarının diğerlerine kıyasla daha az salınım gösterdiği sonucuna ulaşılabilmektedir.

Tablo 2. Tanımlayıcı İstatistikler

\begin{tabular}{lccccccc}
\hline & Ort. & Medyan & Çarpiklık & Basıklık & Jarque-Bera & Olasılık & Gözlem \\
\hline IKO & 48.375 & 47.450 & 0.229 & 1.526 & 17.465 & 0.000 & 176 \\
\hline$\dot{\text { ISO }}$ & 43.389 & 43.450 & 0.055 & 1.500 & 16.588 & 0.000 & 176 \\
\hline$\dot{\text { IO }}$ & 10.270 & 9.900 & 0.958 & 3.182 & 27.145 & 0.000 & 176 \\
\hline GíO & 18.866 & 18.100 & 1.112 & 3.776 & 40.661 & 0.000 & 176 \\
\hline TDİO & 12.455 & 12.100 & 0.961 & 3.194 & 27.389 & 0.000 & 176 \\
\hline
\end{tabular}

Tablo 3'te işgücüne katılım ve istihdam oranları için ADF ve PP testleri sonuçları yer almaktadır. Test sonuçlarına göre; ele alınan işsizlik serileri ve bunlara ait pozitif ve negatif şoklardan oluşan seriler birinci farkta I(1) durağandır ve bu sonuçlara göre histeri hipotezi geçerlidir.

Tablo 3. İşgücüne Katılım ve İstihdam Oranlar İçin ADF ve PP Birim Kök Test Sonuçlan

\begin{tabular}{|c|c|c|c|c|c|c|c|c|c|}
\hline & Sabit & & Sabit & \& Trend & & Sabit & & Sabit & \& Trend \\
\hline & t-ist. & Prob. & t-ist. & Prob. & & t-ist. & Prob. & t-ist. & Prob. \\
\hline \multirow{6}{*}{ 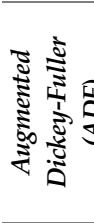 } & -0.23 & 0.93 & -2.67 & 0.25 & \multirow{8}{*}{$\begin{array}{l}\frac{\mathrm{d}(\mathrm{ISO})}{\mathrm{d}(\mathrm{ISOP})} \\
\frac{\mathrm{d}(\mathrm{ISON})}{\mathrm{d}(\mathrm{I} K O)} \\
\mathrm{d}(\mathrm{IKOP})\end{array}$} & -10.17 & $0.00^{\mathrm{a}}$ & -10.15 & $0.00^{\mathrm{a}}$ \\
\hline & -0.45 & 0.90 & -2.62 & 0.27 & & -9.23 & $0.00^{\mathrm{a}}$ & -9.20 & $0.00^{\mathrm{a}}$ \\
\hline & -1.70 & 0.43 & -3.00 & 0.14 & & -11.64 & $0.00^{\mathrm{a}}$ & -11.70 & $0.00^{\mathrm{a}}$ \\
\hline & -0.84 & 0.80 & -1.84 & 0.68 & & -7.10 & $0.00^{\mathrm{a}}$ & -7.09 & $0.00^{\mathrm{a}}$ \\
\hline & -0.74 & 0.83 & -1.81 & 0.70 & & -9.18 & $0.00^{\mathrm{a}}$ & -9.18 & $0.00^{\mathrm{a}}$ \\
\hline & -0.52 & 0.88 & -2.75 & 0.22 & & -7.04 & $0.00^{\mathrm{a}}$ & -7.02 & $0.00^{\mathrm{a}}$ \\
\hline \multirow{5}{*}{ 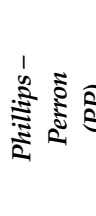 } & -0.12 & 0.94 & -2.41 & 0.37 & & -10.05 & $0.00^{\mathrm{a}}$ & -10.02 & $0.00^{\mathrm{a}}$ \\
\hline & -0.31 & 0.92 & -2.30 & 0.43 & & -8.81 & $0.00^{\mathrm{a}}$ & -8.78 & $0.00^{\mathrm{a}}$ \\
\hline & -1.65 & 0.45 & -3.03 & 0.13 & $\mathrm{~d}(\mathrm{IIKON})$ & -11.63 & $0.00^{\mathrm{a}}$ & -11.65 & $0.00^{\mathrm{a}}$ \\
\hline & -0.90 & 0.79 & -1.71 & 0.74 & $\mathrm{~d}$ (İSO) & -9.88 & $0.00^{\mathrm{a}}$ & -9.86 & $0.00^{\mathrm{a}}$ \\
\hline & -0.79 & 0.82 & -1.38 & 0.86 & $\mathrm{~d}$ (İSOP) & -9.06 & $0.00^{\mathrm{a}}$ & -9.05 & $0.00^{\mathrm{a}}$ \\
\hline ISON & -0.40 & 0.91 & -2.20 & 0.49 & $\mathrm{~d}(\mathrm{ISON})$ & -10.68 & $0.00^{\mathrm{a}}$ & -10.65 & $0.00^{\mathrm{a}}$ \\
\hline
\end{tabular}

${ }^{a},{ }^{b}$ ve $^{c}$ sirasiyla $\% 1, \% 5$ ve $\% 10$ anlam düzeyini ifade eder. 
Yapısal kırılmalı olarak yapılan analizde sonuçlar aşağıdaki tablo 4'teki gibidir. İsgücüne katılım oranı serisinde (IKO) histeri etkisi yapısal kırılmalarla birlikte geçerlidir ve yapısal kırılma tarihleri 2006 Kasım ve 2014 Temmuz aylarına denk gelmektedir. İşü̈cün katılım oranlarının pozitif şoklarından oluşan seri (IKOP) için ADF ve PP birim kök testlerine göre histeri etkisi geçerliyken yapısal kırılmalarla bakıldığında histeri etkisi yoktur, bu seri için yapısalcı yaklaşım geçerlidir. Negatif şoklardan oluşan seride (IKON) ise sabitteki kırılmaları inceleyen Model A sonuçlarına göre 2007 Ocak ve 2018 Şubat aylarında yapısal kırılmalarla birlikte birim kök vardır ve histeri etkisi geçerlidir. Sabit + trendde kırılmaları inceleyen Model C'ye göre yapısalcı yaklaşım geçerlidir. Model C'nin sunduğu sonuçların Model A'ya kıyasla daha güvenilir kabul edilmesine karşına burada işgücüne katılımdaki azalmaların emek talebinin mahiyetinde bir değişimden kaynaklı olduğu yorumuna kapı aralamaktadır.

Tablo 4. İşgücüne Katılım, İstihdam Oranlarına Ait LM Birim Kök Testi Sonuçlan

\begin{tabular}{|c|c|c|c|c|c|c|c|}
\hline & \multicolumn{2}{|c|}{ Model A } & \multicolumn{5}{|c|}{ Model C } \\
\hline & $\mathrm{CV}$ & KT & $\mathrm{CV}$ & $1 \%$ & $5 \%$ & $10 \%$ & KT \\
\hline İKO & -1.64 & 2010M01-2010M11 & -5.35 & -6.48 & -5.78 & -5.48 & 2006M11-2014M07 \\
\hline İKOP & $-3.44^{\mathrm{c}}$ & 2012M08-2013M12 & $-5.89^{b}$ & -6.39 & -5.70 & -5.39 & 2013M10-2014M10 \\
\hline İKON & -1.99 & 2007M01-2018M02 & $-5.46^{c}$ & -6.25 & -5.56 & -5.21 & 2007M01-2016M06 \\
\hline İSO & -1.66 & 2007M01-2014M01 & -5.02 & -6.28 & -5.72 & -5.41 & 2009M09-2017M06 \\
\hline ISOP & -1.98 & 2009M06-2010M11 & -4.39 & -6.32 & -5.81 & -5.49 & 2009M06-2015M07 \\
\hline ISON & -1.92 & 2007M01-2010M04 & $-6.26^{a}$ & -6.25 & -5.56 & -5.21 & 2008M11-2018M01 \\
\hline
\end{tabular}

Model A için \%1, \%5 ve \%10 Kritik Değerleri strastyla: -4.088; -3.580 ve -3.323'tür.

${ }^{a},{ }^{b}$ ve c sirasiyla $\% 1, \% 5$ ve \%10 anlam düzeyini ifade eder.

CV-Kritik Değer ve KT-Kırılma tarihlerinin kısaltmasıdır.

İstihdam oran (ISO) ve istihdam oranlarındaki pozitif değişimler (İSOP) serileri için histeri etkisi yapısal kırılmalarla birlikte geçerlidir. Yapısal kırılma tarihleri İSO için 2009 Eylül ve 2017 Haziran, İSOP için 2009 Haziran ve 2015 Temmuz'dur. İSON için (IKON'a benzer şekilde) Model A histeri etkisinin 2007 Ocak ve 2010 Nisan tarihlerinde yapısal kırılmalarla birlikte geçerli olduğunu işaret ederken Model C yapısalcı yaklaşımın geçerli olduğunu ifade etmektedir. Burada da yapısal kırılmaların türünün histeri etkisi üzerinde etkili olduğu sonucuna ulaşılabilir.

İşsizlik oranları üzerinden inceleme yapıldığında; genel, genç ve tarım dışı işsizlik oranları ile bunlardaki pozitif ve negatif şoklardan oluşan serilere ait 
ADF ve PP test sonuçları aşağıdaki tablo 5'te sunulmaktadır. Buna göre ele alınan bütün seriler I(1) fark durağandır ve histeri hipotezi hepsi için geçerlidir.

Tablo 5. Genel, Genç ve Tarmm Dışı İşsizlik Oranları İçin ADF ve PP Birim Kök Test Sonuçları

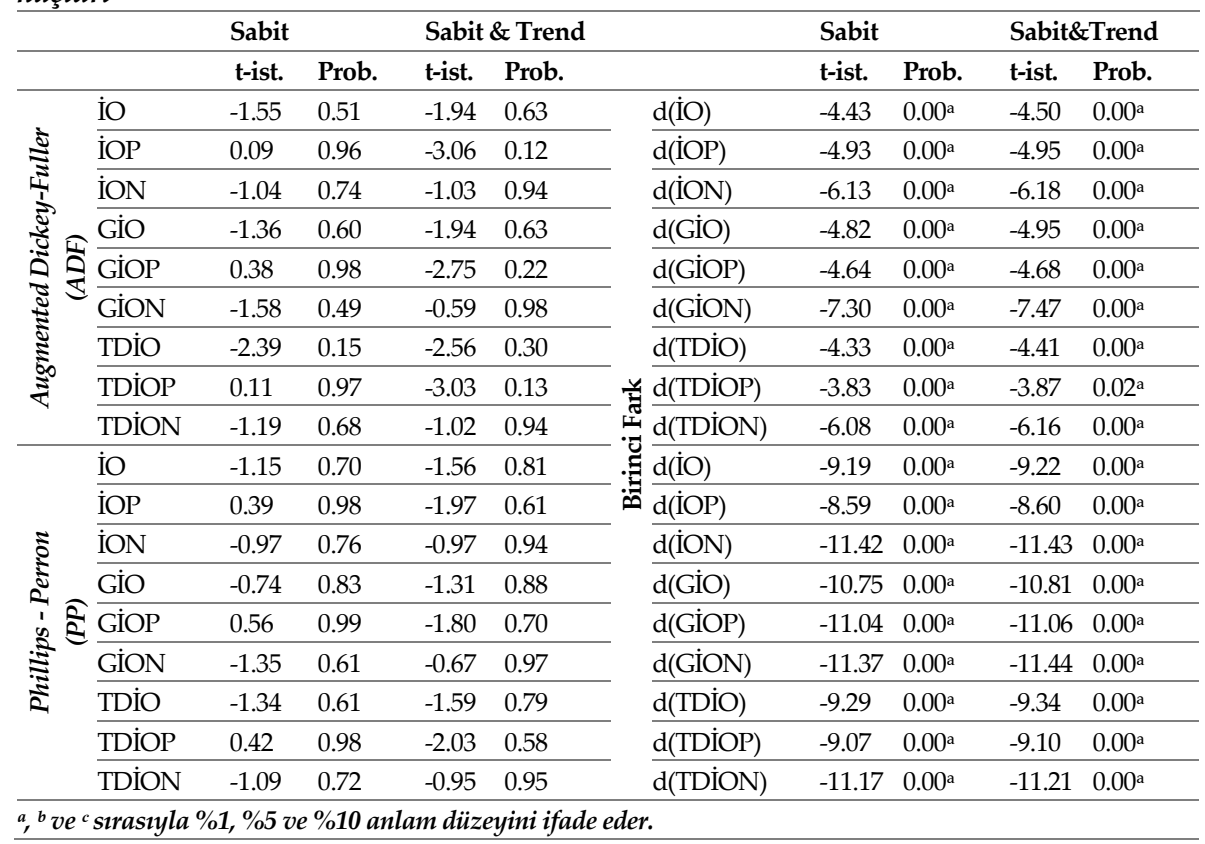

İlgili seriler için LM testi sonuçları tablo 6'da yer almaktadır. Yapısal kırılmalar dikkate alındığında; İO'nun Model A'ya göre 2009 Kasım ve 2010 Mayıs aylarında yapısal kırılmayla birlikte birim kök içerdiği ancak sabit + trenddeki değişimleri ele alan Model C'ye göre birim kökün olmadığı ve yapısalcı yaklaşımın geçerli olduğu görülmektedir. Bununla birlikte İOP ve İON serilerinde histeri etkisi yapısal kırılmalarla birlikte geçerlidir. İP için yapısal kırılmalar 2008 Eylül ve 2010 Ağustos iken İON için 2008 Mart ve 2011 Temmuz'dur.

GİO, GİP ve GİN serileri için histeri etkisi yapısal kırılmalarla birlikte geçerlidir. GİO için yapısal kırılmalar 2008 Ekim ve 2011 Mayıs'tır. GİP için 2009 Temmuz ve 2016 Ağustos, GİN için 2008 Şubat ve 2010 Aralık'tır. 
Tablo 6. Genel, Genç ve Tarım Dışı İşsizlik Oranlarna Ait LM Birim Kök Testi Sonuçlan

\begin{tabular}{|c|c|c|c|c|c|c|c|}
\hline & \multicolumn{2}{|c|}{ Model A } & \multicolumn{5}{|c|}{ Model C } \\
\hline & $\mathrm{CV}$ & KT & $\mathrm{CV}$ & $1 \%$ & $5 \%$ & $10 \%$ & KT \\
\hline İO & -3.078 & 2009M11-2010M05 & $-6.092^{b}$ & -6.52 & -5.775 & -5.401 & 2008M10- 2011M05 \\
\hline IOP & -3.085 & 2008M01- 2016M11 & -4.697 & -6.151 & -5.593 & -5.304 & 2008M09-2010M08 \\
\hline ION & -2.311 & 2009M06- 2013M04 & -4.779 & -6.52 & -5.775 & -5.401 & 2008M03-2011M07 \\
\hline GIOO & -2.978 & 2009M06-2010M03 & -5.33 & -6.52 & -5.775 & -5.401 & 2008M10- 2011M05 \\
\hline GIOP & -3.077 & 2010M10- 2016M06 & -5.038 & -6.285 & -5.722 & -5.414 & 2009M07- 2016M08 \\
\hline GION & -1.897 & 2009M05-2010M01 & -3.819 & -6.52 & -5.775 & -5.401 & 2008M02- 2010M12 \\
\hline TDIO & -3.259 & 2009M10- 2010M10 & $-6.078^{b}$ & -6.52 & -5.775 & -5.401 & 2008M08- 2011M05 \\
\hline TDIOP & -3.304 & 2008M01- 2010M03 & -4.552 & -6.151 & -5.593 & -5.304 & 2008M07- 2010M08 \\
\hline TDION & -2.279 & 2009M12- 2010M05 & -4.652 & -6.52 & -5.775 & -5.401 & 2008M03- 2011M06 \\
\hline
\end{tabular}

Model A için \%1, \%5 ve \%10 Kritik Değerleri strasıyla: -4.088; -3.580 ve -3.323'tür.

${ }^{a},{ }^{b}$ ve ${ }^{c}$ strasiyla $\% 1, \% 5$ ve $\% 10$ anlam düzeyini ifade eder.

KT-Kirlma Tarihlerinin kısaltmasıdır.

TDİO Model A'ya göre 2009 Ekim ve 2010 Ekim tarihlerinde yapısal kırılmaya uğramakta ve histeri etkisi göstermektedir. Ancak makbul olan Model C'ye göre bakıldığında yapısalcı yaklaşım geçerlidir. TDİP ve TDİON serileri için histeri etkisi yapısal kırılmalarla birlikte geçerlidir. Yapısal kırılma tarihleri sirasiyla 2008 Temmuz - 2010 Ağustos ve 2008 Mart - 2011 Haziran'dır.

\section{Değerlendirme ve Sonuç}

İşsizlik; tarih boyunca önemini koruyan özellikle de sanayi devrimi sonrasında bütün toplumların doğrudan ve dolaylı olarak gündeminde bulunan çok boyutlu bir kavramdır. Yapay zekâ, robotlaşma, endüstri 4.0, dijitalizm, makinaların interneti ve benzeri kavramların konuşulduğu günümüzde istihdamın geleceği ve işsizlik konusunda sürekli çalışmalar yapılmakta, mevcut politikaların etkinliği, verimliliği ve tutarlılığı konusunda arayışlar devam etmektedir. Bu kapsamda yapılan çalışmalardan biri de sosyoekonomik ve politik anlamda yaşanan kriz ve şoklardan sonra işsizlik oranlarının denge istihdam düzeyine dönüp dönemediğiyle ilgilidir. Bu noktada işsizlik serisinin şoklar karşısındaki tutumunu gösteren doğal oran hipotezi, histeri hipotezi ve yapısalcı yaklaşım öne çıkmaktadır. Doğal oran işsizlik serisindeki şokların zamanla etkisini kendiliğinden yitireceğini -müdahaleye gerek ol- 
madığını- vurgularken, histeri hipotezi makroekonomik müdahaleler yapılmaksızın başlangıç denge düzeyinin yeniden sağlanamayacağını ifade etmektedir. Yapısalcı yaklaşım ise şokların serilerdeki yapısal kırılmalardan meydana geldiğini ve histeri etkisinin olmadığı bu durumda makroekonomik müdahalelere gerek olmadığın belirtmektedir. Buradan hareketle histeri hipotezinin, kamu müdahalelerinin varlığı, gerekliliğini ve meşruiyetini göstermesi bakımından önemli olduğu bu nedenle de yetkililer tarafından itinayla takip edildiği görülmektedir.

Bu çalışmanın ilk aşamasında, bardağın dolu kısmına odaklanılarak, işgücüne katılım ve istihdam oranlarını ve bunlardaki şokları içeren seriler analiz edilmiştir. İlgili literatürden farklı olarak ele alınan bu değişkenler ADF ve PP testine göre fark durağandır, başka bir ifadeyle bu değişkenler için histeri hipotezi geçerlidir, şoklar kalıcı etkide bulunmaktadır. Yapısal kırılmaları veren LM testi sonuçlarına göre; işgücüne katılım oranı serisinde histeri etkisi yapısal kırılmalarla birlikte geçerlidir. Yapısal kırılma tarihleri 2006 Kasım ve 2014 Temmuz'dur. İşü̈cüne katılım oranlarındaki pozitif ve negatif şokları ifade eden serilerde doğal oran hipotezi geçerlidir. İkinci aşamada bardağın boş kısmına bakılmakta ve Türkiye için genel, genç ve tarım dışı işsizlik serileri ile bu serilerdeki negatif ve pozitif şoklardan oluşan seriler incelenmektedir. Bu seriler ADF ve PP testlerine göre histeri etkisi göstermektedir. Sonuçlar -benzer testleri kullanmış olan- Yılancı (2009), Koçyiğit vd. (2011), Saraç (2014), Bayrakdar (2015), Ağazade (2016), Taş ve Uğur (2017) ve Akkuş ve Topuz (2019)'un çalışmalarıyla örtüşmektedir. LM testi sonuçları ise İO ve TDİO için yapısalcı yaklaşımın geçerli olduğu ancak bunun da trenddeki yapısal kırılmalardan kaynaklandığı görülmektedir. Diğer değişkenler için histeri etkisi yapısal kırılmalarla birlikte geçerlidir. Burada yapısal krizlerin 2008 yılında ve 2010-11 yıllarında yoğunlaşmış olması, Küresel Finans Krizi'nin ve Arap ayaklanmaları ve Gezi parkı gibi süreçlerin Türkiye ekonomisi üzerindeki etkilerinin kalıcı olduğu sonucuna ulaşılmaktadır. Genel ve tarım dışı işsizlik oranlarını ifade eden serilerin yapısalcı yaklaşıma uygun olarak hareket etmesi; Çınar vd. (2014) tarafından sunulan sonuçları teyit etmektedir. Genç işsizlik serisindeki histeri etkisi Yavuzaslan vd. (2017) ile uyumludur.

Analizlerden elde edilen bulgular bir arada değerlendirildiğinde; (a) serilerin şoklarına ayrıştırılarak analiz edilmesinin gizli histeri (hidden hysteresis) etkilerini ortaya çıkarabileceği, (b) işgücüne katılım ve istihdam oranlarındaki şoklarda yapısal kırılmaların belirleyici olduğu, (c) küresel gelişmeler 
ve iç dinamiklerin işgücü piyasalarını etkilediği ve yapısal kırılmalara neden olabildiği, (d) genel ve tarım dışı işsizlik oranlarının şoklardan geçici olarak etkilendiğii, (e) genç işsizlik oranları için histeri hipotezinin geçerli olduğu, (f) genel, genç ve tarım dışı işsizlik oranlarına ait pozitif ve negatif şoklardan oluşan serilerde histeri etkisinin olduğu tespit edilmiştir.

Bu tespitler Blanchard ve Summers (1986) tarafından öne sürülen fiziki sermaye modeli kapsamında değerlendirildiğinde, son yıllarda takip edilen özelleştirme stratejileri ve uygulanan politikalar neticesinde Türkiye'de bir taraftan faaliyet gösteren fabrikaların özelleştirildiği, kapandığı veya kapatıldığı, ekilebilir arazi miktarında azalmanın olduğu gözlemlenirken diğer taraftan yeni üretim sahalarının ve istihdam olanaklarının şekillendiği gözlemlenmektedir. On beş yıla yakın bir süreci ele alan bu süreçte fiziki sermaye stokundaki değişmelerin genel ve tarım dışı işsizlikte olmasa bile bu serilerin şoklarında ve genç işsizlik serisinde histeri etkisinin oluşmasına neden olduğu, bunda da son yıllarda genişleyen hizmet sektörünün payı olduğu düşünülebilir. Beşerî sermaye modeli merkezinde bakıldığında süreç içinde geçim sıkıntısının artıyor olması ve sosyokültürel olarak çalış(a)mama ve işsizlik durumlarının mahalle baskısına maruz kalıyor olması gibi nedenlerle histeri etkisinin genel ve tarım dışı işsizlik için söz konusu olmadığı görülmektedir. İçerdekiler-dışardakiler modeli çerçevesinde bulgular değerlendirildiğinde, sendikalaşma oranının sadece \%15ler civarında seyretmesi ve toplumun (en azından büyük bir kısmının) kültürel olarak sadece kendi çıarını düşünme gibi davranışlardan uzak olması nedenleriyle Türkiye'de bu modelin pek geçerli olmadığı düşünülmektedir. Bununla birlikte, özellikle yatay ve dikey hareketlilikten-göçlerden kaynaklı olarak tanıdıkçılık-hemşericilik ve akrabacılık gibi kayırmacılık türlerinin (kısmen de olsa) etkili olduğu unutulmamalıdır. Son olarak elde edilen bulgular, bu çalışmada yazar tarafından öne sürülen, teknolojik dönüşüm modeli'yle uyum göstermektedir. Buna göre, üretim süreçlerini modernize hale getiren firmalar görece daha düşük istihdam kapasitesi yaratmaktadır ve bu durumda beklentileri yüksek olan eğitimli gençlerin istihdam edilmelerini zorlaştırmakta ve genç işsizlik serisinde histeri etkisi geçerli olmaktadır. Ayrıca teknolojik olarak büyük çaplı dönüşümlerin olduğu bu süreçte ekonomik şoklar sonrasında firmaların yeni sayfa yaklaşımı etkisiyle sofistike işlemler için modern teknolojiye geçmeleri genç işsizlik oranlarının kalıcı olarak etkilenmesi sonucunu doğurabilmektedir. 
Sonuç olarak, Türkiye'de işgücüne katılım, istihdam, genel işsizlik, genç işsizlik ve tarım dışı işsizlik gibi işsizlik serisi bileşenlerinin farklı karakteristikler göstermektedir. Doğal oran ve histeri hipotezleri ile yapısalcı yaklaşım ele alınan işsizlik türüne göre değişebilmektedir. Bardağın dolu tarafını temsil eden işgücüne katılım ve istihdam oranları için histeri hipotezi geçerlidir. Bu serilerdeki şoklar kalıcı etkide bulunmaktadır ve makroekonomik istikrar için müdahale edilmelidir. Bardağın boş tarafını işaret eden genel işsizlik ve tarım dışı işsizlik serileri için yapısalcı yaklaşım geçerlidir ve bu seriler için yapısal kırılmalarla birlikte doğal oran hipotezi geçerlidir. Bu serilerde yaşanan şokların yapısal kırılmalardan kaynaklandığı ve zaman içinde dengeye döneceği görülmektedir. Kamu otoritelerinin bu serilerin temsil ettiği kesimler için dengeye dönüşü hızlandırıcı mahiyette dolaylı müdahalelerde bulunmalarında yarar vardır. Genç işsizlik serisi ise işsizlik türlerinin zayıf karnıdır ve en kırılgan olan bu seri için histeri hipotezi geçerlidir. Yetkililerin; genç işsizliğin nedenleri arasında sayılan, eğitim sisteminin geliştirilmesi, teknolojik adaptasyon, uygulamalı eğitim, mesleki eğitim, sertifikasyon ve sübvansiyonlar gibi alanlar başta olmak üzere doğrudan ve dolaylı politik hamleleri ivedilikle yapmaları gerekmektedir. Bütün bunların yanı sıra ilgili değişkenlerdeki pozitif ve negatif şokların incelenmesi ve bunlardaki histeri etkisi araştırılması da etkin strateji tayininde önemlidir. Yetkililerin gerek küreselyerel gelişmeleri ve bunların ülkeye olası yansımalarını incelerken, gerekse de uygulayacakları politikaları oluştururken istihdam yapısındaki farklılıklara dikkat etmeleri ve ülke gerçeklerine uygun şekilde makroekonomik politika setine odaklanmaları gerekmektedir. 


\section{EXTENDED ABSTRACT}

\section{Validity Of The Unemployment Hysteresis Hypothesis In Turkey: Multidimensional And Asymmetrical Approach \\ Musa Öztürk \\ Isparta University of Applied Sciences}

The transformations experienced in the globalization process cause the emergence of socioeconomic and political shocks worldwide. One of the variables that can be both the cause and the result of these shocks is unemployment. Unemployment means that the labor factor is not used fully and/or effectively and labor is a unique factor of production in which production and consumption relations can be taken together. With this feature, it differs from other production factors, and it can carry and trigger shocks at the same time. It's the same situation for Turkey and unemployment are among the constants of the national agenda as the most important macroeconomic problems. For this reason, it is precisely followed by those concerned. Despite the average annual economic growth of $4.5 \%$ during the period since 1980, the unemployment problem is not resolved. This situation brings up the concept of "jobless growth", which indicates that economic growth cannot produce enough employment. In discussions on the characteristic of unemployment data against shocks, three basic approaches come to the fore as the natural rate hypothesis, unemployment hysteresis hypothesis, and structuralist approach. The natural unemployment rate; states that unemployment rates will converge to a level of balance that will not accelerate inflation in the long run, and shocks will not have permanent effects. Unemployment hysteresis hypothesis; expresses that shocks have permanent effects. Accordingly, after the shocks experienced in the series, a new normal occurs and the new general balance is shaped around this rate. The structuralist approach states that the natural unemployment rate can be affected by macroeconomic variables, institutional functioning, and endogenous dynamics, and states that structural breaks should be taken into account. Econometrically, which hypothesis 
or approach is valid is examined by unit root tests. If the series is stationary, the shocks experienced do not have a permanent effect and this indicates that the natural rate hypothesis is valid. If there is a unit root in the series, the hysteresis hypothesis is valid. The structuralist approach indicates that the unemployment rate becomes stationary when structural breaks are allowed.

The hysteresis hypothesis in unemployment rates is especially important in the Phillips curve, which indicates that there is a trade-off between inflation and unemployment. Blanchard and Summers (1986) stand out in the discussions on the reasons why the hysteresis effect is valid in unemployment rates. According to these researchers who have examined the unemployment rates for European countries, the emergence of the hysteresis effect can be explained in three different ways as physical capital, human capital, and insider-outsider models. First, the physical capital model states that in economic contraction processes, firms will decrease their capital stock (negative supply shock) and thus there will be shrinkage in demand for labor for the next period, thereby triggering long-term unemployment. The human capital model states that shocks will cause the unemployed workforce to lose their skills and motivations and companies will turn to young people who have long-term potential. The third method is the insider-outsider model. Accordingly, insiders act as a monopoly and only insiders (employees-employees) can negotiate on the wages, and outsiders (unemployed) have no role in this. Besides, unemployed people would have lost their skills over time and therefore have problems in reaching the beginner level of post-shock unemployment series. Also it is stated that working in a good job is prestige and working in a bad job is a kind of "stigma". It is stated that long-term unemployment is also a kind of stigma and the stigmatized workforce is moving away from the necessary communication and interaction channels, and in this process, the increase in productivity wage makes the decrease in employment permanent. The other approach states that institutional causes such as layoffs, capital constraints, lack of coordination-error may be effective in the emergence of the hysteresis effect.

In this study, the technological transformation model and the new page approach are proposed as a new and original perspective on approaches to the emergence of the hysteresis effect. According to the technological 
transformation model; Unemployment becomes permanent since the technology internalized in the production, management, and consumption processes is developing very rapidly and the unemployed people cannot adapt to the newly employed technologies due to the shocks. In addition, as new technologies tend to imitate the activities of high wages, the demand for intermediate staff increases, which does not require much qualification, and this may indirectly lead to an increase in the number of educated unemployed and permanent increase. The new page approach states that, as a result of shocks, firms will reduce the amount of labor they employ, and after the shock, they will open up a new page and turn to investments with higher / new technology to reduce the labor demand of the firm. The technological transformation model and new page approach are thought to be one of the current causes of unemployment hysteresis. In the human capital model proposed by Blanchard and Summers (1986), it is stated that the hysteresis effect will arise the loss of skill and motivation due to long-term unemployment, but in the technological transformation model, it is stated that the hysteresis effect will occur because of not being adapted to this transformation. When viewed at the firm scale, it is seen that the new page approach will strengthen the effect of the technological transformation model and this will affect the workforce in the middle and upper age groups, especially those who cannot adapt to advanced technology.

In the first stage of this study, by focusing on the full part of the glass, the series including the labor force participation and employment rates and the shocks in them were analyzed. According to the ADF ve PP test results, the hysteresis hypothesis is valid for these variables, shocks have a permanent effect. According to the results of the LM test, which gives structural breaks, the hysteresis effect is valid with structural breaks for the labor force participation rate. Structural breaking dates are November 2006 and July 2014. The natural rate hypothesis is valid for the series that express positive and negative shocks in labor force participation rates. In the second stage, the empty part of the glass is checked. For Turkey General, young and non-agricultural unemployment rate series and negative and positive shocks in these series are examined. These series show hysteresis effect according to ADF and PP tests. The results are compatible with the literature, which used similar tests. As for the LM test results, it 
is seen that the structuralist approach is valid for IO and TDIO, but this is due to the structural breaks in the trend. For other variables, the hysteresis effect is valid with structural breaks. Structural breaking dates are concentrated between 2008 and 2010-11 when processes such as the Global Financial Crisis and Arab uprisings and Gezi Park were experienced. The structuralist approach is valid for the General and non-agricultural unemployment rate series and it is partially suitable for the relevant literature. The hysteresis hypothesis is valid in the youth unemployment series.

When the findings obtained from the analyzes are evaluated together; (a) the analysis of the series by decomposing them into shocks may reveal the effects of hidden hysteresis, (b) structural breaks are determinant in shocks in labor force participation and employment rates, (c) global developments and internal dynamics affect labor markets and can cause structural breaks, (d) general and non-agricultural unemployment rates are temporarily affected by shocks, (e) the hysteria hypothesis is valid for youth unemployment rates, (f) It has been determined that there is a hysteria effect in the series consisting of positive and negative shocks of general, youth, and non-agricultural unemployment rates.

When these determinations are evaluated within the scope of the physical capital model, the model can be considered to be partially descriptive. It is seen that the human capital model is not valid. Insider - outsider model is also not valid. Because only $15 \%$ of the workforce is a member of the trade unions and traditional patterns are largely valid in business processes. Finally, the findings obtained are in line with the technological transformation model proposed by the author in this study. Accordingly, companies that modernize their production processes create relatively lower employment capacities, making it difficult to employ educated young people with high expectations and the hysteria effect in the youth unemployment series. In addition, after the economic shocks, the transition of companies to modern technology for sophisticated transactions with the effect of a new page approach may result in the permanent unemployment rate being affected.

As a result, the unemployment series components such as labor force participation, employment, general unemployment, youth unemployment, and non-agricultural unemployment show different characteristics. 
The natural rate hypotheses, hysteresis hypotheses, and the structuralist approach can change according to the type of unemployment. The hysteresis hypothesis is valid for labor force participation and employment rates representing the full side of the glass. Shocks in this series have a lasting effect and should be intervened for macroeconomic stability. For the general unemployment and non-agricultural unemployment series, which indicate the empty side of the glass, the structuralist approach is valid, and the natural rate hypothesis is valid for these series with structural breaks. It is seen that the shocks experienced in these series are caused by structural breaks and will return to balance in time. It is beneficial for public authorities to make indirect interventions that accelerate the return to balance for the sectors represented by these series. The young unemployment series is the weak belly of unemployment types and the hysteresis hypothesis applies to this most fragile series. Authorities should examine the symmetrical and asymmetrical hysteresis effects and pay attention to the hidden hysteria effect to follow correct and consistent policies.

\section{Kaynakça / References}

Acemoğlu, D. (2002). Technical change, inequality and the labor market. Journal of Economic Literature. XL, 7-72.

Ağazade, S. (2016). Türkiye için işsizlik histerisine karşın doğal oran hipotezinin doğrusal dışı yöntemlerle sınanması. SGD-Sosyal Güvenlik Dergisi, 6(2), $28-46$.

Akcan, A. (2018). Tarım ve tarım dışı sektörlerde işsizlik histerisi. Tarım Ekonomisi Dergisi, 24(1), 21-32.

Akcan, A. (2019). Türkiye'de gençlerin işsizlik histerisi. Kastamonu Üniversitesi İktisadi ve İdari Bilimler Fakültesi Dergisi, 21(1), 31-47.

Akerlof, G. A. (1984). An economist theorist's book of tales. Cambridge: Cambridge University Press.

Akkuş, Ö. ve Topuz, S. (2019). İşsizlik histerisinin geçerliliğii: Gelişmekte olan en kırılgan beşli. Sosyoekonomi, 27(39), 69-80.

Arellano, M. ve Bond, S. (1991). Some tests of specification for panel data: Monte Carlo evidence and an application to employment equations. Review of Economic Studies, 58, 277-297.

Bai, J. ve Perron, P. (1998). Estimating and testing linear models with multiple structural changes. Econometrica, 66(1), 47-78. 
Bai, J. ve Perron, P. (2003). Computation and analysis of multiple structural change models. Journal of Applied Econometrics,18,1-22.

Barışık, S. ve Çevik, E. İ. (2008). Yapısal kırılma testleri ile Türkiye'de işsizlik histerisinin analizi: 1923-2006 dönemi. Karamanoğlu Mehmetbey Üniversitesi Sosyal ve Ekonomik Araştırmalar Dergisi, 1, 109-134.

Bayrakdar, S. (2015). Türkiye için işsizlik histerisi ya da doğal işsizlik oranı hipotezinin geçerliliğinin sınanması. Journal of Economic Policy Researches, 2(2), 45-61.

Baysal Kar, B. (2019). İşsizlik histerisi mi? doğal işsizlik oranı mı? Farklı kapitalizm türleri için bir analiz. Bolu Abant İzzet Baysal Üniversitesi Sosyal Bilimler Enstitüsü Dergisi, 19(2), 271-298.

Blanchard, O. J. ve Summers, L. H. (1986). Hysteresis and the european unemployment problem. NBER Macroeconomics Annual, Vol.1, MIT Press.

Bozkurt, E. ve Altıner, A. (2018). Doğrusal ve doğrusal olmayan birim kök testleriyle Türkiye' de işsizlik histerisinin tespiti. Uluslararası İktisadi ve İdari Incelemeler Dergisi, UIIIID-IJEAS, (Prof. Dr. Harun Terzi Özel Sayısı), 167180.

Bulutay, T. (1995). Employment, unemployment and wages in Turkey, Ankara:ILO Yayınları, 214-220,256-262.

Camarero, M.; Carrion-i-Silvester, J. L. ve Cecilio, T. (2006). Testing for hysteresis in unemployment in OECD countries: New evidence using stationarity panel tests with breaks. Oxford Bulletin of Economics and Statistics, 68(2), 167-182.

Caner, M. ve Hansen, B. E. (2001). Theshold autoregression with a unit root. Econometrica, 69(6),1555-1596.

Carrion-i-Silverstre, J. L.; Kim, D. ve Perron, P. (2009). GLS-Based unit root tests with multiple structural breaks under both the null and alternative hypotheses. Economic Theory, 25, 1754-1792.

Carrion-i-Silverstre, J. L. (2005b). Health care expenditure and GDP: Are thy broken stationary? Journal of Health Economics, 24(5), 939-854.

CTRS, (2017). Kadir Has Üniversitesi Türkiye Çalışmaları Merkezi - Türkiye sosyal-siyasal eğilimler araştırması. https://www.khas.edu.tr/tr/haberler/kadir-hasuniversitesi-turkiye-sosyal-siyasal-egilimler-arastirmasi-2017-sonuclari adresinden erişilmiştir.

Cuestas, J. C. ve Javier, O. (2014). Smooth transitions, asymmetric adjustment and unit roots. Applied Economics Letters, 14(21),969-972. 
Çelik, C. ve Küçükkale, Y. (2018). İşgücü piyasasına yönelik histeri etkisi: Ratchet modeli ile Türkiye örneği. Uluslararası İktisadi ve İdari İncelemeler Dergisi, (Prof. Dr. Harun Terzi Özel Sayısı), 21-40.

Çınar, M., Kanalıcı Akay, H. ve Yılmaz, F. (2014). A sectoral analysis of hysteresis in unemployment: Evidence from Turkey. Bilig, 69, 29-52.

Christopoulos, D. K. ve León-Ledesma, M. A. (2007). Unemployment hysteresis in EU countries: What do we really know about it? Journal of Economic Studies, 34(2), 80-89.

Doğru, B. (2014). Euro bölgesinde işsizlik histerezisinin ikinci nesil panel birim kök testleri ile analizi. Anadolu Üniversitesi Sosyal Bilimler Dergisi, 14(3),7786.

Gregory, R. (1985). Wages policy and unemployment in Australia. Paper presented at the Cheiwood Gate Conference on Unemployment, Cheiwood Gate.

Güloğlu, B. ve İspir, M. (2011). Is natural rate of unemployment or hysteresis? Sector-specific panel unit root test analysis for Turkey. Ege Academic Review, 11(2), 205-216.

Güriş, B.; Tiftikçigil, B. Y. ve Tıraşoğlu, M. (2015). Testing for unemployment hysteresis in Turkey: Evidence from nonlinear unit root tests. Quality \& Quantity, $1-12$.

Idikut Özpence, A. ve Ergen, E. (2017). Analysis of unemployment hysteresis in Turkey: Structural break unit root test. Journal of Economics Finance and Accounting, 4(4),368-376.

Im, K. S.; Lee J. ve Tieslau M. (2005). Panel LM unit root tests with level shifts. Oxford Bulletin of Economics and Statistics, 67(3), 393-419.

Im, K. S.; Lee J. ve Tieslau M. (2005). Panel LM unit root tests with trend shifts. FDIC Center for Financial Research Working Paper No.2010-1.

Kahyaoğlu, H. Tüzün O. Ceylan, F. ve Ekinci R. (2016). İssizlik histerisinin geçerliliği: Türkiye ve seçilmiş $\mathrm{AB}$ ülkeleri üzerine bir uygulama. Celal Bayar Üniversitesi Sosyal Bilimler Dergisi, 14(4), 103-128.

Kapetanios, G. (2005). Unit-root testing against the alternative hypothesis of up to m structural breaks. Journal of Time Series Analysis. 26, 123-133.

Kapetanios, G. Shin, Y. ve Andy, S. (2003). Testing for a unit root in the nonlinear star framework. Journal of Econometrics, 112(2), 359-379.

Karagöz, K. ve Saraç, T. (2016). İşsizlikte histeri etkisinin kalman filtresi yaklaşımiyla incelenmesi: Türkiye örneği. Aydın İktisat Fakültesi Dergisi, 1(2), 5972. 
Koçyiğit, A., Bayati, T. ve Tüfekçi, A. (2015). Türkiye'de işsizlik histerisi ve star modelleri uygulaması. Marmara Üniversitesi İktisadi ve İdari Bilimler Dergisi, 31(2), 45-60.

Kutlu, S. ve Yurttagüler, İ. (2017). İşsizlikte histerisiz etkisinin uzun hafıza modeli ile incelenmesi: Türkiye üzerine bir uygulama. İsletme ve İktisat Çalş̧malarn Dergisi, 5(4), 68-78.

Kwiatkowski, D.; Phillips, P.; Schmidt, P. ve Shin, Y. (1992). Testing the null hypothesis of stationarity against the alternative of a unit root: How sure are we that economic time series have a unit root? Journal of Econometrics, 54(1-3), 159-178.

Lee, C. (2010). Testing for unemployment hysteresis in nonlinear heterogeneous panels: International evidence. Economic Modelling, 27, 1097-1102.

Lee, J. ve Strazicich, M. C. (2003). Minimum lagrange multiplier unit root test with two structural breaks. The Review of Economics and Statistics, 85(4),10821089.

Lee, J. ve Strazicich, M. C. (2004). Minimum LM unit root test with one structural break. Appalachian State University Working Papers, no.04-17,1-15.

Lindbeck, A., ve Snower, D. (1985). Wage setting, unemployment and insider outsider relations. Institute for International Economic Studies, Stockholm, Working Paper-344.

Lumsdaine, R. L. ve Papell, D. H. (1997). Multiple trend breaks and the unit root hypothesis. The Review of Economics and Statistics, 79(2),212-218.

Mitchell, W. ve Muysken, J. (2008). Full employment abandone. Cheltenham: Edward Elgar

$\mathrm{Ng}$, S. ve Perron, P. (1995). Unit root tests in ARMA models with data-dependent methods for the selection of the truncation lag. Journal of the American Statistical Association, 90(429), 268-281.

O'Shaughnessy, T. (2011). Hysteresis in unemployment. Oxford Review of Economic Policy, 27(2), 312-337.

Özcan, B. (2015). İşsizlik histerisi hipotezi OECD ülkeleri için geçerli mi? yapısal kırılmalı birim kök analizi. Erciyes Üniversitesi İktisadi ve İdari Bilimler Fakültesi Dergisi, 40, 95-117.

Pazarlığlu, M. ve Çevik, E. (2007). Ratchet model: 1939-2005 dönemi Türkiye uygulaması. Trakya Üniversitesi Sosyal Bilimler Dergisi, 9(1), 17-34.

Perron, P. (1997). Further evidence on breaking trend functions in macroeconomic variables. Journal of Econometrics, 80(2), 355-385. 
Phelps, E. S. (1994). Structural slumps: The modern equilibrium theory of unemployment, interest, and assets. Harvard University Press, Cambridge.

Phillips, P. C. B. ve Perron, P. (1988). Testing for unit roots in time series regression. Biometrika, 75(2), 335-346.

Pissarides, C.A. (1992). Loss of skill during unemployment and the persistence of employment shocks. Quarterly Journal of Economics, 107(4),1371-91.

Saraç, T. (2014). Hysteresis effect in unemployment: Turkey case. Ege Academic Review, 14(3), 335-344.

Sessions, J.G. (1994). Unemployment stigma and multiple labour market equilibria: A social-psychological explanation of hysteresis. Labour, 8(3), 355-75.

Sollis, R. (2009).A simple unit root test against asymmetric star nonlinearity with an application to real exchange rates in nordic countries. Economic Modelling, 26(1), 118-125.

Şanlı, D. (2018). Makro ekonomik istikrarsızlıklar ve doğal işsizlik oranı: 19802016 OECD ve Türkiye ekonomisi örneği. Bulletin of Economic Theory and Analysis, 3(3), 159-174.

Taş, S. ve Uğur, B. (2017). Türkiye için işsizlik histerisi mi, Yoksa doğal oran hipotezi mi geçerlidir? Çukurova Üniversitesi İktisadi ve İdari Bilimler Fakültesi Dergisi, 21(1), 25-45.

Tekin, İ. (2018). Türkiye'de işsizlik histerisi: Fourier fonksiyonlu durağanlık sınamaları. Dokuz Eylül Üniversitesi İktisadi İdari Bilimler Fakültesi Dergisi, 33(1), 97-127.

Tokatlıoğlu, İ.; Öztürk, F. ve Ardor, H. N. (2014). AB ülkeleri ve Türkiye işgücü piyasasında histeri etkisi: RATCHET modeli analizi. Sosyoekonomi, 22(22), 297-320.

Topalhan, T., Durusoy, Ö. ve Özdemir, Z . (2017). İşsizlik oranı üzerindeki şoklar gerçekten kalıcı mı: Türkiye ekonomisi üzerine bir analiz. SGD-Sosyal Güvenlik Dergisi, 7(2), 87-104.

Tunal, H. (2010). The analysis of unemployment in Turkey: Some empirical evidence using co-integration test. European Journal of Social Sciences, 18(1), 18-38.

Yavuzaslan, K.; Damar, Ö.; Sönmez, B.; Özdaş, B.; Uyar, N. ve Akılotu, E. (2017). Türkiye'de genç işsizliğinin, işsizlik histerisi hipotezi çerçevesinde yap1sal kırılmalar testi ile analizi. Aydın Iktisat Fakültesi Dergisi, 2(2), 21-32.

Yılanc, V. (2009). Yapısal kırılmalar altında Türkiye için işsizlik histerisinin sınanması. Doğuş Üniversitesi Dergisi, 10(2), 324-335. 
Yıldırım, S. ve İnançlı, S. (2018). Türkiye'de işsizlik histerisis hipotezinin geçerliliğinin ampirik olarak değerlendirilmesi. Ekonomik ve Sosyal Araştırmalar Dergisi, 14, 45-54.

Yıldırım, S. (2011). Türkiye'de histeri hipotezinin geçerliliğinin çoklu yapısal kırılmalı ckp birim kök testiyle sinanması. Akdeniz Üniversitesi İktisadi ve İdari Bilimler Fakültesi Dergisi, 11(22), 28-47.

Zivot, E. ve Andrews, D. (1992). Further evidence on the great crash, The oil price shock, and the unit root hypothesis. Journal of Business \& Economic Statistics, 10(3), 251-270.

\section{Kaynakça Bilgisi / Citation Information}

Öztürk, M. (2020). Türkiye'de işsizlik histerisi hipotezinin geçerliliği: Çok boyutlu ve asimetrik yaklaşım. OPUS-Uluslararası Toplum Araştırmaları Dergisi, 15(10. Yıl Özel Sayıs1), 4882-4910. DOI: 10.26466/opus. 725553 